\title{
LA ELECCIÓN POPULAR
}

\author{
THE PEOPLE'S CHOICE \\ Lucrecia ESCUDERO CHAUVEL \\ EHESS-Laboratoire MOMA CERMA (Paris) \\ lescuderochauvel@gmail.com
}

\begin{abstract}
Resumen: El tweet de Joe Biden, The people had spoke, refiriéndose al voto del pueblo americano en las recientes elecciones presidenciales, recuerda el título del célebre libro de P. F. Lazarsfeld, B. Berelson y H. Gandet, The People Choice, dedicado a las elecciones de 1940. Como se sabe, la obra se centraba en la forma en que los electores del estado de Ohio decidían su voto en las elecciones del 5 de noviembre de 1940, donde el presidente saliente Franklin D. Roosevelt (demócrata), que iba por su cuarta reelección, se oponía a Wendell Willkie. Merece la pena repasar las conclusiones de esa investigación a la luz de las recientes elecciones americanas y, subsidiariamente, interrogarnos por los usos sociales de la actualidad en la construcción del directo televisivo.
\end{abstract}

Palabras clave: Elecciones americanas. Usos sociales de los medios. Construcción de la noticia. Sociosemiótica.

\begin{abstract}
Joe Biden's tweet "The people had spoken", referring to the vote of the American people in the recent presidential elections, recalls the title of Paul Lazarsfeld's et alii famous book The People Choice research dedicated to the 1940 elections. As is known, the investigation focused on the way Ohio state voters decided their vote in the November 5, 1940 election that opposed outgoing President Franklin D. Roosevelt (Democrat) who was going for his fourth re-election to his challenger Wendell Willkie. It is worth reviewing the conclusions of these founding investigations in the light of the recent American elections and, alternatively, to consider the current social uses in the construction of the television direct.
\end{abstract}

Keywords: American elections. Social uses of the media. Construction of the news. Sociosemiotic.

\section{LA INTERACCIÓN COMUNICATIVA EN LA DECISIÓN DEL VOTO Y LA PERCEPCIÓN SELECTIVA}

El tweet de Joe Biden, The people had spoke, refiriéndose al voto del pueblo americano en las recientes elecciones presidenciales, recuerda el título del célebre libro 
de P. F. Lazarsfeld, B. Berelson y H. Gandet, The People Choice (1944), una investigación dedicada a las elecciones de 1940. Como se sabe, dicha investigación se centraba en la forma en que los electores del estado de Ohio decidían su voto en la elección del 5 de noviembre de 1940, donde el presidente saliente Franklin D. Roosevelt (demócrata), que iba por su cuarta reelección, se oponía a Wendell Willkie. Elegido con el 54,7 \% de los votos, Roosevelt batió el récord de presidentes reelectos y fue a partir de 1951 cuando se enmendó la Constitución imponiendo el limite a dos mandatos consecutivos.

La investigación dio origen a la teoría del low-effect de los medios y fue revolucionaria porque, en pleno auge de la poderosísima industria de la publicidad (strong-effect), Lazarsfeld y su equipo demostraron que, en un ejercicio de microsociología electoral, que el grupo primario de la familia, los amigos, los vecinos o la comunidad religiosa resultan decisivos a la hora de decidir el voto. Esta investigación se completa con la realizada en 1955 con su discípulo Eliú Katz, conocida como la teoría del Two Step Flow, sobre la influencia del leader de opinión, las interacciones interpersonales y la comunicación directa. Ambas teorías resultaron fundamentales para pensar la sociología electoral y los alcances de la comunicación política en el uso de los medios (Maigret, 2003: 77 y ss.).

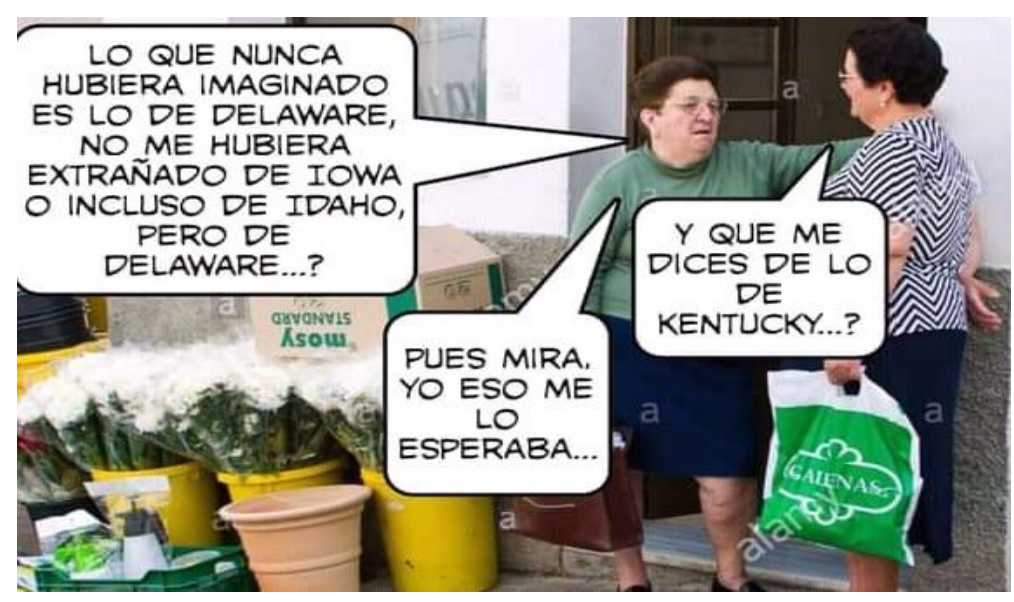

Imagen 1. En la era de los blogueros y los medios asociativos, la influencia personal vuelve a la actualidad.

Merece la pena repasar las conclusiones de estas investigaciones fundadoras a la luz de las recientes elecciones americanas y, subsidiariamente, plantearnos los usos sociales de la actualidad en la construcción del directo televisivo.

En primer lugar, hay que considerar el efecto filtro por el que no escuchamos o estamos ciegos a los mensajes que no van en la dirección de nuestras creencias; los efectos de los medios son limitados por procesos selectivos de memoria individual y colectiva e imaginarios sociales, que se articulan con las clásicas variables de edad, sexo, situación social y familiar. En segundo lugar, los individuos no están solos frente a los medios, sino que poseen una fuerte competencia mediática y un imaginario simbólico que les 
permitirán la construcción de pequeños mundos como forma de entender el flujo de noticias.

En el mundo posible de las elecciones, el mundo mediático ha estudiado abundantemente los guiones (scripts) de estos procesos, que incluyen desenlace exitoso, fraude, contestación y finalmente triunfo. Se trata de una secuencia narrativa clásica, que no llega a la síntesis del héroe / villano, pero que tiene todos los componentes de una saga tradicional con traidores como la cadena Fox, los estados que cambian de orientación como Georgia o Pennsylvania, los adyuvantes que tratan de explicar y dar razones de la actitud del presidente, y los opositores del presidente electo que denuncian fraude. Así, los electores de Trump funcionaban con la creencia en el triunfo de su candidato y estaban ciegos a cualquier otra información, salvo la emanada por el propio presidente en sus tweets ${ }^{1}$.

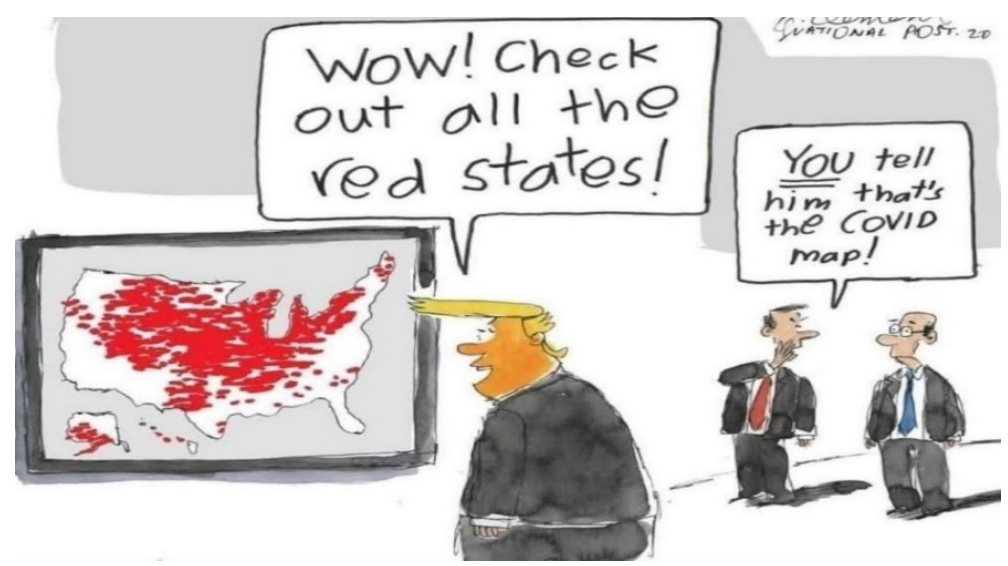

Imagen 2. Ceguera selectiva.

La declinación de la función regulativa de los partidos políticos hace que los medios ocupen una función rectora en la construcción de la agenda de los problemas públicos (Peñamarín, 2016). Los medios producen la ilusión de una sociedad consensual, aunque lo que veamos sean comunidades interpretativas y permanentes negociaciones sobre el contenido de los hechos. En síntesis, una sociedad conflictiva y polémica que construye laboriosos consensos antes de pronunciarse en la delegación de poder. Las palabras del expresidente Barak Obama, pronunciadas luego de conocerse los resultados de la histórica elección, van en este sentido: la perversión de Trump es haber sembrado la duda en la fortaleza del sistema democrático americano.

\section{LA NOTICIA: PURO ARTEFACTO MEDIÁTICO}

Esto nos lleva a otro problema estrechamente ligado, como es el de la narración de la actualidad. Ejercicio absoluto del despliegue del aparato formal de la enunciación, tal y

\footnotetext{
${ }^{1}$ Para la teoría de los mundos posibles, véase Eco (1979 y 1994). Este mismo efecto de ceguera colectiva se verificó en 1982 durante la Guerra Falklands-Malvinas (Escudero Chauvel, 1996).
} 
como lo definía el lingüista Émile Benveniste (1963), el relato de los medios está puntuado por referencias espacio-temporales: el aquí y ahora que, como en el orden dramático aristotélico, sitúan al receptor. La actualidad es un puro artefacto semiomediático, ligado a la temporalidad, a la forma en que los medios construyen la percepción de este tiempo. Puro artefacto porque esta temporalidad está sostenida en un dispositivo de visibilidad y por esto es clave en los procesos de mediatización ciudadana. Si el hecho es del orden de lo real, la noticia es del orden de lo discursivo.

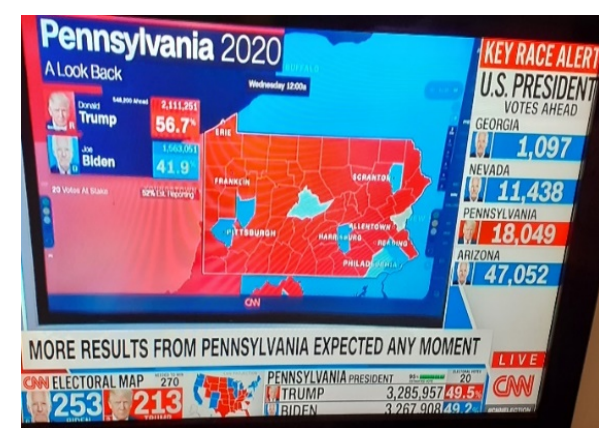

Imagen 3. Construcción del pasado: A look back.

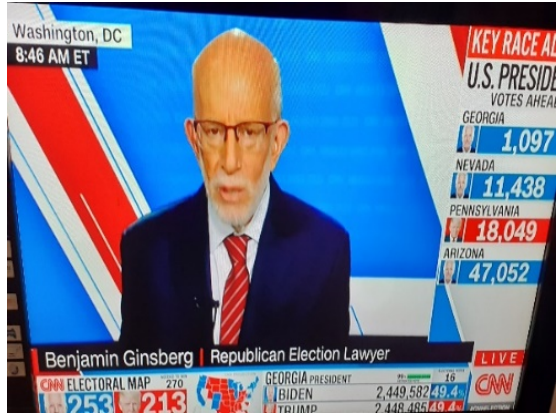

Imagen 4. Construcción del presente: Washington 8:46 AM.

La dimensión performativa de la noción de actualidad moldea permanentemente nuestra percepción de los eventos y de sus encuadres. En cuanto tal, es un dispositivo técnico-discursivo pilar del género informativo que transforma el hecho (fact) en noticia, a partir del uso de estrategias semiolingüísticas específicas, creando lo que Jorge Lozano ha llamado "la historicidad presentista" (en Lozano y Martín, 2018).

Así, ambas imágenes muestran la función deíctica que cumple el género informativo en la gestión del pasado para entender el presente y, simultáneamente, la caución del directo televisivo y del flujo de información on live, que fue la gran invención de la CNN en la década de los noventa del siglo pasado.
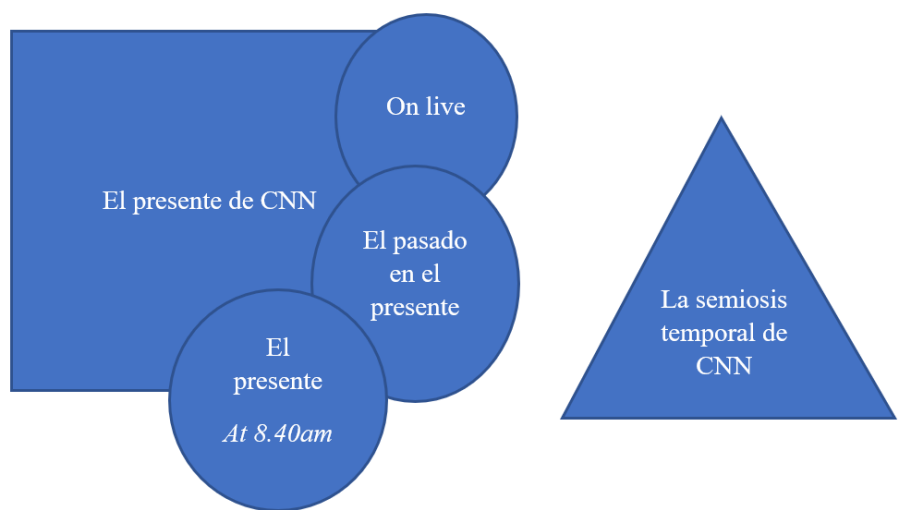

Imagen 5. La representación del tiempo según $\mathrm{CNN}$. 
No hay una duración objetiva de la actualidad. Hemos visto que un pasado se hace presente en el directo (Live) de CNN con la finalidad de su explicación, gracias al pacto enunciativo emisor / receptor. Un contrato implícito sobre la regla de cómo debe ser percibido el discurso y bajo qué régimen de actualidad lo registramos es lo que nos permite adscribir ese momento como actualmente acaecido. Un poder que otorga la sociedad a la institución mediática para contarnos la verdad de los hechos, haciendo una amalgama entre lo realmente acaecido y la verdad de su enunciación televisiva.

Es la distinción teórica crucial entre el estar ahí y el haber estado ahí lo que actualiza la CNN: This is CNN está ahí para contarnos el despliegue informativo del mundo global. Pero el efecto no es solo la difusión informativa; es la caución de verdad, como en el momento dramático de la definición del voto, de mostrar los mecanismos de conteo y de evolución de las estadísticas en tiempo real. Para aquellos que lo siguieron como yo, fue un maratón de tres días sin interrupción. Un evento mediático total.

Este concepto, desarrollado por Daniel Dayan y Eliú Katz (1992), se aplica perfectamente aquí para caracterizar la producción informativa de $\mathrm{CNN}$ : los eventos mediáticos socializan a los ciudadanos a la forma de la acción política y su funcionamiento; son pedagógicos respecto a un sistema básicamente opaco. El maratón televisivo de CNN, y, sucesivamente, el de la histórica jornada de la toma del Capitolio por los seguidores de Trump, el 6 de enero 2021, muestran algo más. Son un signo ennoblecedor de la función televisiva: CNN aporta transparencia a la confrontación política, neutraliza los intermediarios (en directo) mostrando todo el espectro político y, subsecuentemente, refuerza la percepción de que John Biden iba acercándose a la presidencia lenta pero irreversiblemente.

Este efecto acumulativo de aporte de pruebas - el espectador podía ver que se estaban contando los votos en directo - tuvo el efecto de producción de verosimilitud; pero puede también tener en contra un efecto narcotizante, de pegado a la pantalla. Sin embargo, una de las conclusiones a las que llegaba el estudio de Dayan y Katz (1992) en su momento, es que este tipo de ceremonia mediática, tanto la elección como el debate, contribuyen a la integración nacional, donde la audiencia televisiva funciona como el simulacro del consenso.
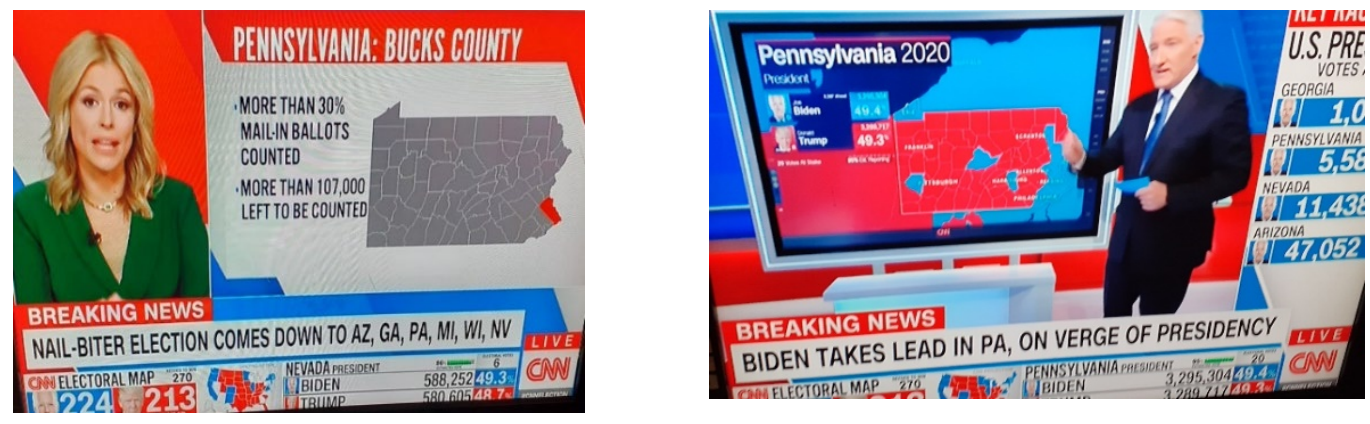

Imágenes 6 y 7. El periodista John King explicando condado por condado la elección en Pennsylvania y, sucesivamente, barrio por barrio el voto de Filadelfia. La fuerza ilocutiva mayor fue dar confianza al electorado demócrata. 
Fundadoras del efecto de verdad, estas dos imágenes reforzadas por los deícticos gestuales muestran el modo en que la actualidad no es ni pasado ni presente; es una forma televisiva, al igual en que un meme es una forma clásica de la circulación de mensajes en la red. Y esto es moderno: al tiempo largo de los ciclos de la naturaleza y de las sociedades tradicionales, sobreviene el tiempo sincopado de la noticia, ritmado por los acontecimientos que, como en la teoría de la circulación de la mercancía en Marx, debe ser siempre más rápido para que rinda más. Para Andrea Semprini (1997 y 2003), la irrupción de la red vuelve posible la multiplicación de los planos de la realidad. Es decir, de mundos posibles de significación y de referencia que dan un sentido y una legibilidad a la experiencia, e incide sobre la transformación de la temporalidad social que se refleja desde la moda (el cambio de tendencias); los horarios de los comercios de 24 horas siete días a la semana; la organización del tiempo libre: ritmo individual/ritmo colectivo/ritmo mediático.

\section{LA BATALLA DE GEORGIA}

Quienes conocen el nombre de este estado americano por la inolvidable canción "Georgia of my Mind", compuesta en 1930 por Hoggy Carmicle e inmortalizada por Ray Charles, tal vez no sepan que es el estado original de Martin Luther King, con una población afroamericana de sus dos terceras partes. Vale la pena resumir someramente su historia para comprender mejor lo que significó esta batalla voto a voto.

Posesión española desde 1629 e invadida por tropas inglesas en 1739, Georgia se convirtió en 1788 el cuarto estado que integraba la futura United States of América. Durante la Guerra de Secesión (1864), el general Sherman destruyó y finalmente conquistó Savannah, su entonces capital, y esta batalla está indeleblemente anclada en el imaginario social gracias a la película Lo que el viento se llevó (1939), interpretada por Vivian Leight y Clark Gable. En 1957, el Civil Rights Act permitió el voto a la población afroamericana y hasta la llegada al poder de John F. Kennedy las escuelas, medios de transporte y restaurantes, entre otros espacios públicos, estaban segregados. No obstante, el voto de Georgia fue establemente republicano desde 1964.

La batalla decisiva por el número de 16 electores necesarios para asegurar el triunfo demócrata se dio en el escrutinio de este estado, que cambió su tradicional voto republicano hacia el voto democrático, lo que dio el triunfo definitivo a Joe Biden. Una de las explicaciones posibles de este cambio se atribuyó a las terribles violencias policiales que tuvieron lugar durante el mandato de Donald Trump y a la anulación del Obama Care, el sistema de cobertura universal que había permitido el acceso a la salud de una población completamente marginalizada durante la administración Barak Obama. 


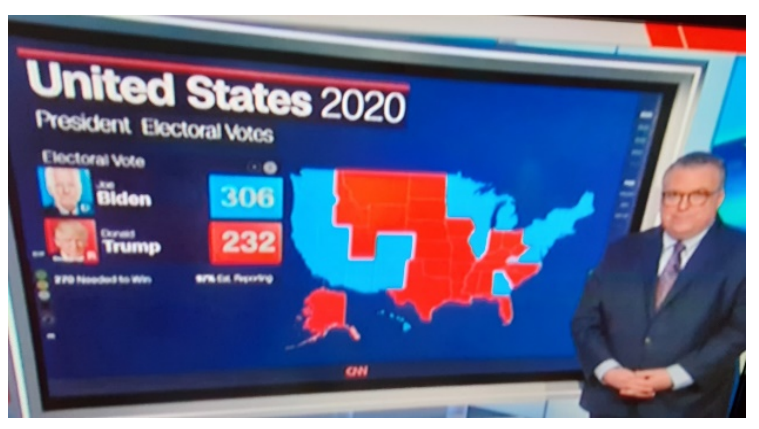

Imagen 8. "Dramatic moment in the American history". Clímax informativo en el que CNN anuncia el triunfo de Biden a las 17.30 del viernes 12/11. Temporalidad de la política e impaciencia de los medios.

Tenemos clara la distinción entre dar a conocer un hecho, función tradicional del género informativo, de la producción de la actualidad, que es una práctica social característica de las sociedades mediatizadas. La batalla de Georgia había sido precedida por una puesta en marcha por parte de Donald Trump de un mundo posible mediático, donde la única explicación causal a la derrota era el fraude. En la conferencia de prensa de la Casa Blanca, Trump instala la duda sobre la veracidad del conteo contra toda evidencia y sin aportar pruebas. Y es ahí donde se produce el anticlímax informativo: inmediatamente después, todas las cadenas de información americanas, NBC, CBS, ABC, CNN e incluso Fox y Aljezeera decidieron no publicitar los tweets del presidente, por tratarse de una información no verificable. Le cortaron, literalmente, la palabra, privándolo de su arma comunicativa favorita: la red social. Lo extraordinario de la situación es la inmediata licuación del poder del presidente en la noche del jueves 5 al viernes 6 de noviembre.

La rapidez con que las agencias de comunicación y los principales estados occidentales con la excepción de Rusia y China reconocieron inmediatamente el triunfo demócrata, muestra el consenso global sobre el final de la era Trump. Es cierto que se instaló durante varios días una negociación sobre el sentido de la situación que creó suspense: ¿es una regla constitutiva o regulativa en el ritual republicano el hecho de que el presidente saliente no felicitara a su sucesor? Pero el empecinamiento de Trump perdió importancia - e interés informativo - cuando los medios informativos cambiaron de mundo posible y se pasó a una nueva agenda, la del presidente electo, dedicada a la pandemia del COVID-19 que llevaba causadas más de 300.000 muertes $^{2}$.

\footnotetext{
${ }^{2}$ El martes 20 de enero, último día de gobierno de Trump, la cifra aumentó a cuatrocientos mil muertos, más perdidas que durante la guerra del Vietnam.
} 

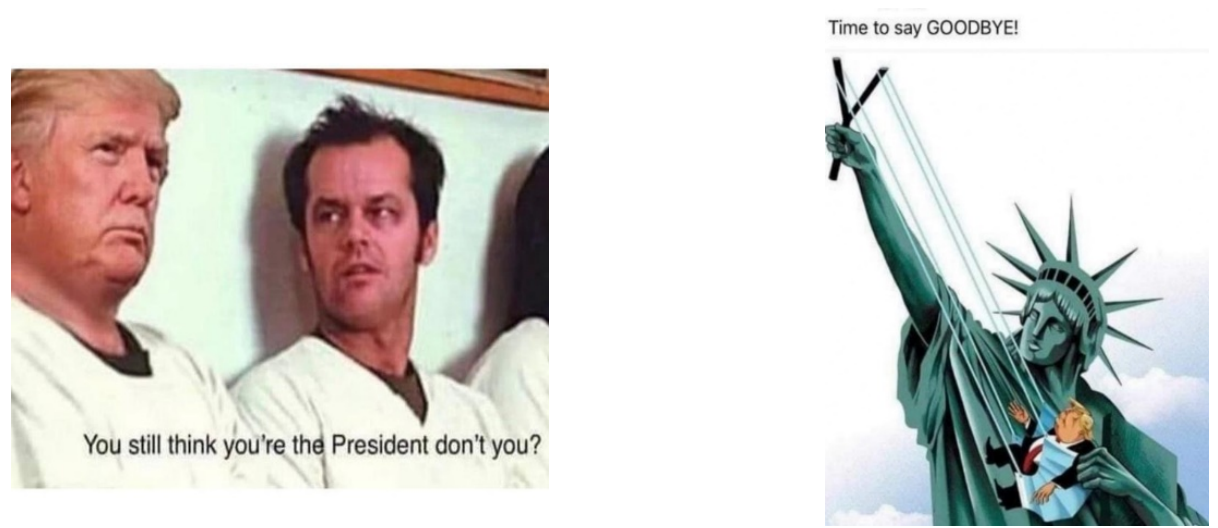

Imágenes 9 y 10. Los memes explotaban mientras se transmitía la conferencia de prensa de Trump.
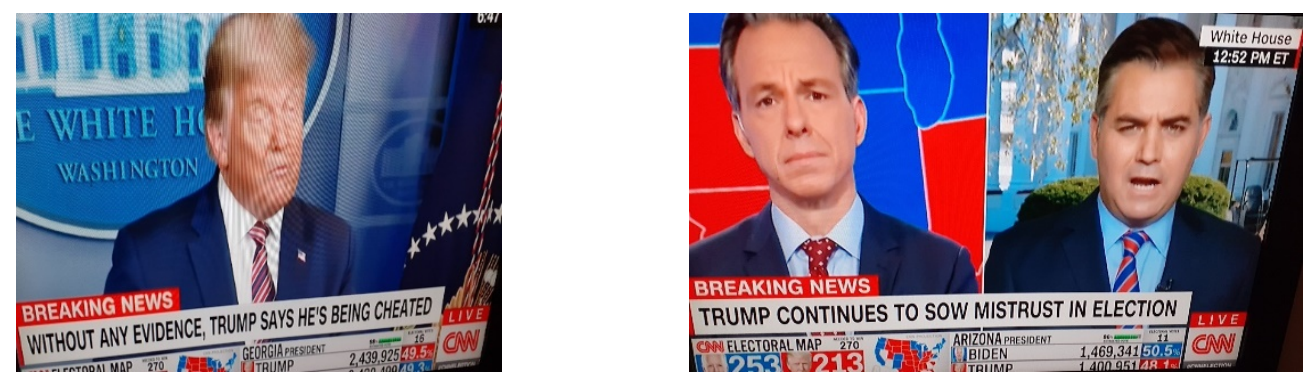

Imágenes 11 y 12. Conferencia de prensa de Donald Trump acusando de fraude electoral.

\section{CONCLUSIONES}

Los eventos del 6 de enero con la irrupción en el Capitolio de una horda de seguidores de Trump dispuestos a invalidar la elección —el equivalente de las Torres Gemelas, pero en política interna - abren una serie de interrogantes para los analistas de la relación entre medios y esfera pública: la fragilidad del sistema democrático frente a los ataques masivos de desinformación. Se calcula en más de veinte mil fakes news enviadas desde el Twitter de Trump durante su mandato; la ruptura del contrato social que enmarca la lucha política; los efectos infantilizadores de las redes y la lógica del like y del foward; por último, lo que se ha llamado la tiranía del algoritmo, que nos vuelve prisioneros de una semioesfera de creencias y preferencias que se repiten infinitamente volviendo a sus usuarios ciegos y sordos a otras perspectivas. Umberto Eco (1987) en su célebre artículo "La guerrilla semiológica", alertaba sobre la necesidad que, frente a cada terminal, sea puesto de televisión, de radio o celular, estuviera alerta un espectador crítico desarrollando una rara habilidad: la del decodificador de mensajes. 


\section{REFERENCIAS BIBLIOGRÁFICAS}

Benveniste, É. (1963). Problèmes de Linguistique Générale. Paris: Gallimard.

ECO, U. (1979). Lector in fabula. Milano: Bompiani. (1987). "Para una guerrilla semiológica". En La estrategia de la ilusión, U. Eco, 177-187. Madrid: Lumen.

(1994). I limiti dell'interpretazione. Milano: Bompiani.

DayAn, D. \& Katz, E. (1992). Media Events. The Live Broadcasting of History. Cambridge: Harvard University Press.

Escudero Chauvel, L. (1996). Malvinas. El gran relato. Fuentes y rumores en la información de guerra. Barcelona: Gedisa.

KAtZ, E. \& LAZARSFeld, P. F. (1955). Personal Influence: The Part Played by People in the Flow of Mass Communication. New York: Free Press.

Lazarsfeld, P. F.; Berelson, B. \& Gandet, H. (1944). The People Choice: How the Voters Make up his Mind in a Presidential Campaign. New York: Duell, Sloan \& Pearce.

LozAnO, J. y MARTin, M., EDS. (2018). Documentos del presente. Madrid: Lengua de Trapo.

Maigret, E. (2003). Sociologie de la Communication et des Médias. Paris: A. Colin.

PEÑAMARín, C. (2016). "La elaboración de emociones y conflictos en la nueva esfera pública". deSignis 24, 35-59.

SEMPRINI, A. (1997). L'information en continu. France Info et CNN. Paris: Nathan (2003). La Société de flux. Formes du sens et identités dans les sociétés contemporaines. Paris: Le Harmattan.

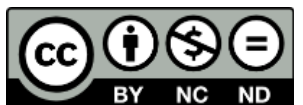

This work is licensed under a Creative Commons AttributionNonCommercial-NoDerivatives 4.0 International (CC BY-NC-ND).

El/la firmante del artículo se responsabiliza de las licencias de uso de las imágenes incluidas.

Fecha de recepción: 11/01/2021

Fecha de aceptación: 28/04/2021 